da

I. Presentación 



\title{
El principio de objetividad de la Administración Presentación
}

\author{
Luis Miguez Macho \\ Profesor titular de Derecho administrativo \\ Universidad de Santiago de Compostela
}

“Artículo 103

1. La Administración Pública sirve con objetividad los intereses generales y actúa de acuerdo con los principios de eficacia, jerarquía, descentralización, desconcentración y coordinación, con sometimiento pleno a la Ley y al Derecho.

$$
[\ldots] "
$$

Constitución Española de 1978

$$
-I-
$$

El primer artículo que la Constitución Española de 1978 dedica específicamente a la Administración pública, el 103, comienza con una proclamación que no tiene precedentes en nuestro constitucionalismo histórico y tampoco encuentra fácil parangón en el constitucionalismo comparado: la Administración pública sirve con objetividad los intereses generales. Esta afortunada fórmula, nacida del debate parlamentario de la Constitución', se ha convertido en la base de la caracterización constitucional de la Administración pública, pero su comprensión no está exenta de dificultades, que llamaron la atención de la doctrina administrativista dando lugar a estudios muy valiosos sobre el tema de relevantes autores como Luis Morell Ocaña, Juan Alfonso Santamaría Pastor o Alejandro Nieto García.

En efecto, la primera perplejidad que siempre ha planteado la objetividad de la Administración es su compatibilidad con el principio, igualmente constitucional y fundamental en un Estado democrático, de la subordinación de aquélla al poder de direc-

1 En concreto, fue introducida prácticamente en sus términos actuales en el debate en comisión del proyecto de Constitución en el Congreso de los Diputados, como resultado de una transacción sobre sendas enmiendas presentadas por el Grupo parlamentario vasco y el profesor Laureano López Rodó (Diario de Sesiones del Congreso de los Diputados núm. 81 de 1978, de 6 de junio, pág. 2959). 
ción política de los órganos de gobierno. La respuesta, como es obvio, radica en que en un Estado democrático de Derecho la Administración obtiene su legitimidad precisamente de su carácter de instrumento objetivo al servicio de los intereses generales bajo la dirección del Gobierno de turno y de su sometimiento pleno a la Ley y al Derecho generados democráticamente, es decir, la Administración no tiene, no puede tener intereses propios, sino que ha de servir los intereses generales tal como son definidos por los órganos políticos legitimados democráticamente y con estricto respeto al principio de legalidad. Pero, al mismo tiempo, el principio de igualdad de todos los ciudadanos ante la ley obliga a la Administración como organización, y a cada uno de sus empleados y agentes individualmente considerados, a desarrollar su actividad sin hacer acepción de personas, lo que no significa ignorar los intereses privados que se ven afectados por esa actividad, sino, justo al contrario, buscar su integración con los intereses generales. Asimismo, la objetividad de la Administración tiene un componente no menos importante de racionalización de la toma de decisiones, que se relaciona de manera directa con el principio constitucional de eficacia de la actuación administrativa.

Ciertamente, para la complejidad de matices que presenta el principio del servicio objetivo por la Administración de los intereses generales, no se puede decir que la producción científica dedicada de forma específica al mismo sea demasiado extensa en nuestro país, a pesar de los estudios pioneros de los autores antes citados. Por eso, cuando se van a cumplir treinta y cinco años de la promulgación del texto constitucional, parece razonable abordar una reconsideración del principio de objetividad de la Administración y de sus exigencias y manifestaciones en los distintos ámbitos de la actividad administrativa. Para ello se ha reunido el concurso de un elenco de expertos en Derecho público, no sólo profesores universitarios, formados ya en el nuevo marco constitucional, que aportan una visión renovada del principio apoyándose en la doctrina, la jurisprudencia y la práctica administrativa generada durante estas últimas décadas.

De acuerdo con un criterio sistemático elemental, estas aportaciones se estructuran en tres partes: una dedicada a las cuestiones generales que plantea el principio de objetividad de la Administración, otra a las principales manifestaciones del mismo en la actividad administrativa (o, cabría decir también, a la manera en que las exigencias derivadas del principio de objetividad se insertan en las distintas facetas de la actividad jurídica de la Administración) y una tercera que pretende ofrecer un breve, pero significativo, panorama comparado del principio que nos ocupa.

$$
- \text { II - }
$$

Son cuatro los estudios que componen la parte dedicada a las cuestiones generales sobre el principio de objetividad. Francisco Manuel García Costa abre el número con una reflexión imprescindible acerca de la "Delimitación conceptual del principio 12 de objetividad: objetividad, neutralidad e imparcialidad", en la que se ocupa de preci- 
sar con rigor el concepto de objetividad y de distinguirlo en su aplicación a la Administración pública de otras nociones próximas, como las de neutralidad e imparcialidad. Particular interés revisten sus consideraciones finales sobre las autoridades administrativas independientes y su discutido encaje en un sistema administrativo como el nuestro, que constitucionalmente se fundamenta en el principio de objetividad de la Administración.

Daniel Berzosa López, con su trabajo sobre "El principio de servicio objetivo a los intereses generales en la Constitución y su traducción legislativa”, se encarga de abordar la perspectiva constitucional del principio de objetividad de la Administración y la manera en que se ha reflejado en el Derecho positivo. El autor enriquece con la visión del especialista en Derecho constitucional el estudio de un principio que, como se ha dicho, hoy señala el punto de partida del engarce entre la Constitución y el Derecho administrativo.

La vertiente jurisprudencial del principio de objetividad se analiza en el trabajo de Juan A. Ureña Salcedo sobre "El principio de servicio objetivo a los intereses generales y su control por los tribunales" y en el de Juan Manuel Alegre Ávila titulado "La Administración sirve con objetividad los intereses generales: unas pinceladas heterodoxas desde la perspectiva procesal". El primero se centra sobre todo en los problemas que para el control jurisdiccional de la objetividad de la actuación administrativa se plantean en los casos en que la ley encomienda a la Administración la concreción de los intereses generales mediante el ejercicio de potestades discrecionales, un complejo desafío para el Estado de Derecho que ha dado lugar en nuestra doctrina administrativa a interesantes polémicas doctrinales. El segundo, que se complementa brillantemente con el anterior, constituye una reflexión sobre las modulaciones que el principio de objetividad de la Administración provoca en el proceso contencioso-administrativo y que matizan el carácter predominantemente subjetivo con el que éste se configura, al menos $a b$ initio, en nuestro Ordenamiento jurídico.

La parte más extensa del número es la dedicada a las diversas manifestaciones del principio de objetividad en la actividad de las Administraciones pública. Es evidente que las exigencias de este principio se proyectan sobre toda la actividad jurídica que desarrolla la Administración, por lo que se ha hecho una selección de los ámbitos o sectores de la misma en los que adquiere mayor relevancia. El primero de ellos es el del procedimiento administrativo, pues tradicionalmente se ha venido considerando que la procedimentalización de la actuación administrativa tiene una fuerte vinculación con el principio de objetividad, tanto por la racionalización que la misma aporta a dicha actuación, como por la función que el procedimiento cumple como instrumento de integración de todos los intereses involucrados en la actividad de la Administración. Yo mismo asumo esta parte con el estudio titulado "El principio de objeti- 
vidad en el procedimiento administrativo", en el que no sólo se abordan las cuestiones clásicas que suscita el tema (la imparcialidad de los responsables de la tramitación y resolución del procedimiento, el procedimiento como cauce de integración de intereses públicos y privados, el procedimiento como cauce de adquisición de los fundamentos objetivos de la resolución), sino que también se lleva a cabo una aproximación a los problemas que para la procedimentalización de la actuación administrativa derivan de la moderna tendencia a externalizar el ejercicio de funciones públicas en entidades privadas colaboradoras de la Administración.

El siguiente ámbito que se analiza es el de la contratación pública, conflictivo y delicado como pocos de la actividad administrativa por el volumen de fondos públicos que se manejan en él. Miguel Ángel Bernal Blay en "El principio de objetividad en la contratación pública” destaca el carácter trasversal de este principio, pues afecta a todos los contratos públicos, sea cual sea su calificación jurídica y el tipo de entidad del sector público que los adjudica, y se aplica en todas las fases de aquéllos: desde la selección del contratista, a través de los requisitos para contratar con el sector público y del establecimiento de criterios objetivos de valoración de las ofertas, hasta la ejecución de los contratos, con especial incidencia en el nuevo régimen de modificación de los mismos. Particular atención se presta a la función del recurso especial en materia de contratación como instrumento de control de la objetividad de la contratación pública.

Una de las partes centrales del número es la que trata del principio de objetividad y el régimen del empleo público. La Administración pública actúa necesariamente por medio de personas, de manera que una de las claves del cumplimiento efectivo del principio constitucional del servicio objetivo por aquélla a los intereses generales está sin ninguna duda en su interiorización por los empleados públicos. Esta cuestión es de tal importancia y complejidad que se ha dividido en dos para su estudio detallado. Por un lado, el artículo "El principio de objetividad en la función pública. (Un análisis desde la jurisprudencia)”, de Jesús Fuentetaja Pastor y Javier Guillén Caramés analiza la vertiente institucional del principio de objetividad en relación con el empleo público, referida a la propia configuración normativa de éste, desde las clases de personal hasta las novedosas técnicas de gestión de recursos humanos, pasando por el decisivo momento de la selección del personal, las formas de provisión de puestos de trabajo o el discutido alcance de la potestad de organización en la función pública, todo ello desde una perspectiva esencialmente jurisprudencial, de gran interés en un ámbito tan casuístico y con tan alto nivel de litigiosidad como es éste. Por otro lado, el trabajo de María Antonia Arias Martínez titulado "El principio de objetividad en el empleo público: la objetividad como deber de los empleados públicos" se ocupa de la vertiente subjetiva del principio en el ámbito del empleo público, relativa a la actuación de cada empleado público individualmente considerado, lo que abarca el deber de objetividad a que éste se halla sometido y sus distintas garantías legales (la abstención y recusación en el procedimiento administrativo, el régimen de incompatibilidades, el régimen disciplinario de los empleados públicos), que se analizan de modo 14 exhaustivo. 
Un ámbito de la actividad jurídica de la Administración en el que las consecuencias del principio de objetividad se han querido abordar con especial atención es el de la potestad administrativa sancionadora, por motivos que son fáciles de entender, si se tiene en cuenta la fuerte incidencia que el ejercicio de aquélla produce en la esfera jurídica de los administrados. Francisco José Rodríguez Pontón en el artículo titulado "El principio de objetividad en el ejercicio de la potestad administrativa sancionadora" trata la cuestión, partiendo de la caracterización ampliamente discrecional que dicha potestad presenta en nuestro Ordenamiento jurídico y los extensos márgenes de apreciación que, en consecuencia, se reconocen a la Administración en su ejercicio y que hacen particularmente necesaria la máxima objetivación posible de sus diversos elementos.

Cierra esta parte del número Gabriel Cabello Martínez con un trabajo sobre "El principio de objetividad en el urbanismo", que se plantea las consecuencias del principio que nos ocupa en otro sector marcado por amplias cotas de discrecionalidad administrativa y en el que, como ocurría en el caso de la contratación pública, se mueven grandes intereses económicos y, además, sociales. El autor orienta su exposición al análisis de las distintas formas en que se manifiesta la adecuación de la actuación pública al principio de objetividad en el ámbito urbanístico, que incluyen la participación ciudadana en la tramitación de los instrumentos de ordenación urbanística, la conexión del principio de objetividad con el principio de interdicción de la arbitrariedad, el control de la desviación de poder, como supuesto típico de vulneración del principio de objetividad, y las técnicas de la abstención y la recusación.

\section{- IV -}

La parte del número dedicada al Derecho comparado se centra en los tres Ordenamientos jurídicos europeos que en el terreno administrativo pueden considerarse más cercanos e influyentes sobre el nuestro, tanto desde el punto de vista legal como doctrinal: el alemán, el francés y el italiano. Para ello se ha recurrido, siguiéndose el mismo criterio que en el caso español, a jóvenes juristas de sólida formación que nos ofrecen una visión actual de sus respectivos Ordenamientos, debidamente asentada en la tradición de cada uno de ellos.

Nikolaus Marsch, del Instituto de Derecho de la Información y Medios de Comunicación de la Universidad de Friburgo en Breisgau (Alemania), jurista de formación franco-alemana (Diplôme international d'administration publique por la ENA de Estrasburgo), se encarga de ilustrarnos sobre "El principio de objetividad en Alemania", en un artículo que se ofrece en cuidada y eficaz traducción al español a cargo de la profesora Silvia Díez Sastre. Aun partiendo de que el Ordenamiento jurídico alemán no consagra expresamente el principio de objetividad, se estudian las diversas normas del mismo que constituyen manifestaciones de aquél, bien en el plano procedimental, como son las dirigidas a garantizar la imparcialidad del funcionario en la tramitación del procedimiento administrativo, bien en el plano sustantivo, donde se 
escogen ejemplos en las distintas formas de la actividad administrativa y en la regulación de la función pública, con llamativas similitudes a nuestro propio Ordenamiento jurídico.

De analizar "Le principe d'objectivité en droit administratif français" se ocupa Benoît Delaunay, profesor de Derecho público en la Universidad París Descartes. Como Marsch respecto del Ordenamiento jurídico alemán, el autor inicia su artículo con la constatación de la falta de reconocimiento positivo del principio de objetividad de la Administración en el Derecho francés, pero, también al igual que el autor alemán, aclara de forma inmediata que ello no impide que se le pueda considerar un principio general no escrito, con muy diversas manifestaciones que aparecen encubiertas bajo otros principios jurídicos (la imparcialidad y la neutralidad de los empleados públicos, la igualdad y la legalidad de la acción administrativa) y con correcciones específicas de su incumplimiento, articuladas a través el régimen deontológico de los empleados públicos y de la sanción de ilegalidad y la exigencia de responsabilidad en los casos de actuaciones administrativas realizadas con falta de objetividad.

Cierra el número una extensa reflexión a cargo de Massimo Monteduro, de la Universidad italiana del Salento, sobre “Il carattere multidimensionale dell'imparzialità amministrativa e il principio di obiettività: riflessioni sull'esperienza italiana”. Frente a los Ordenamientos jurídicos alemán y francés, en Derecho italiano sí está codificado en el propio texto constitucional un principio muy próximo al de objetividad, el de imparcialidad de la Administración, que se recoge junto al del buon andamento (buen funcionamiento) de ésta en el artículo 97 de la Ley fundamental. De ahí que Monteduro oriente sus esfuerzos al deslinde entre objetividad e imparcialidad, una cuestión que, como se ha visto en los trabajos de la primera parte del número, también ha preocupado a la doctrina española, pero que en Italia ofrece el interés añadido de que permite dotar de autonomía propia al principio de objetividad dentro de la compleja variedad de matices que presenta el principio constitucional de imparcialidad de la Administración.

$$
-\mathbf{V}-
$$

Como coordinador del número que el lector tiene en sus manos, una vez concluida la tarea de presentar su contenido, sólo me queda expresar el deseo de que el esfuerzo realizado por todos los autores que han aportado sus contribuciones al mismo merezca su aprobación y resulte de utilidad para seguir avanzando en la construcción de una Administración pública adecuada a los principios y exigencias de un Estado social y democrático de Derecho; una tarea más necesaria que nunca en unos momentos como los actuales, en los que nuestro país vive una profunda crisis económica, que ha derivado en una gravísima crisis de financiación del sector público y, por si algo faltara, en una crisis institucional que pone en cuestión los mismos fundamentos del Estado. Alguna relación tienen, sin duda alguna, las quiebras del principio de 16 objetividad de la Administración en la práctica administrativa con esa crisis institucio- 
nal, por lo que su superación también habrá de pasar por reforzar las garantías para que aquélla de verdad sirva con objetividad los intereses generales y no otros intereses, sean abiertamente privados o espuriamente públicos.

Quiero hacer constar, por último, mi agradecimiento a los autores y demás colaboradores en este número por su dedicación y su paciencia a lo largo del complejo proceso editorial que inevitablemente conlleva una obra de la naturaleza de la presente, agradecimiento que hago extensivo a la dirección de la Revista por haberme confiado la coordinación y a mi maestro, el profesor José Luis Carro Fernández-Valmayor, por sus inestimables consejos, así como a mis compañeros del área de Derecho administrativo de la Facultad de Derecho de Santiago de Compostela, y en especial a Marcos Almeida Cerreda, por su apoyo en el contacto con los autores y en la estructuración del número. 
